\title{
Use of Technology for Undergraduate Engineering Education
}

Bruce A. Black

James S. Demetry
James G. Harris

James R. Jones

\section{Abstract}

California Polytechnic State University, RoseHulman Institute of Technology, University of Alabama at Birmingham, and Worcester Polytechnic Institute have formed a Consortium to develop an al ternative learning environment centered around a workstation comprised of a personal computer interfaced to a video disk and laboratory instrumentation. The first phase in their collective effort has been funded by a one-year NSF grant to develop four instructional modules in the fundamentals of electrical engineering. It has demonstrated how four different universities can work together to agree to standards, and to prepare instructional material that can be shared. The results of the first phase efforts are presented. The second phase will continue the development of instructional modules. The Consortium plans to share its expertise and experience through a series of regional workshops for which funding is being sought from private sources. A national association of universities involved in creating modules will be developed to serve as a focal point through which new modules are subject to peer review and existing modules are distributed. Issues involving organizational form, marketing, distribution and other concerns will be addressed during the project with the goal of making the association a self-sustaining organization. The collective efforts of the Consortium will become a model for shared efforts that address other problems in undergraduate engineering education.

\section{Acknowledgement:}

In addition to the principal investigators listed as authors, the following faculty are participating at each of the four universities of the Consortium: Cal Poly - Emile Attala, Ahmad Nafisi, Mahmood Nahvi; Rose-Hulman, Jeff Froyd, Dave Voltmer; University of Alabama at Birmingham - Dave Connor, Michael Reykoff, Dennis Smith

NSF Footnote: This material is based upon work supported by the National Science Foundation under Grant No. USE-8854620. Any opinions, findings, and conclusions or recommendations expressed in this material are those of the authors and do not necessarily reflect the views of the National Science Foundation.

\section{Introduction}

In response to NSF-sponsored workshops held in Washington, D. C. on May 22, 1986 and in Kansas City, Missouri on May 4-6, 1987, a Consortium of four universities was formed to facilitate the creative use of technologically-assisted instruction (TAI). The Consortium members are California Polytechnic State University at San Luis Obispo (Ca) Poly), Worcester Polytechnic Institute (WPI), The University of Alabama at Birmingham (UAB), and Rose-Huiman Institute of Technology. The Consortium submitted a proposal to NSF in November 1987 to assist development of a set of instructiona) modules accessible using a personal computer based workstation equipped with a video disk player.

The Consortium received a one-year grant from NSF for $\$ 80,000$ which was divided equally among the four institutions. In addition to the NSF support, the four universities have contributed over $\$ 200,000$, and Sun Microsystems has granted the Consortium five Sun $386 i$ machines valued at over $\$ 135,000$. The goals of the present NSF project are to produce four instructional modules, one at each school, using computer-based interactive video disks, to exchange the modules within the Consortium, to evaluate the modules at each institution, and to prepare standards for instructional module development.

\section{Current Status}

There have been four meetings of the Consortium; one at FIE in Santa Barbara in October, 1988, one at Rose-Hulman in December, 1988, one concurrent with a training workshop at Cal Poly in January, 1989, and one at ASEE in Lincoln, Nebraska in June, 1989. To provide a foundation for the development of the modules, three sets of specifications are being developed: one describing the hardware, the second describing the authoring system software, and the third defining the user interface. For hardware development

It should be noted that the original proposal was for a five-year period for over $\$ 3.5 \mathrm{million}$. Considerable effort was made to reduce the scale of the original proposal in response to the reduced funding. 
purposes, the universities are using the Sun $386 i$, which supports both DOS and UNIX and IBM-PC and PS/ 2 machines, and Zenith 386 computers. It is expected that students will use a DOS-based system.

The software baseline is DOS 3.3 and the authoring system to be used is PROPI/PC PILOT developed by ASYS. A special arrangement has been made with ASYS to provide a site license for $\mathrm{Ca} 1$ Poly, as well as to provide a reduced cost license for the other three members of the Consortium.

The user interface is being defined as the modules themselves are being created. It will address items such as help key designation, window display and location, use of color, etc. Four modules, one for each university, have been identified and have been storyboarded. They currently are being programmed with plans to add the video. Cal Poly is developing a module on laboratory errors. Rose-Hulman is developing a module on diode modeling, UAB is developing a module on general lumped elements and principles for their analysis, and WPI is developing a module on the response of circuits with a single energy storage element.

The members of the Consortium have been communicating with each other through electronic mail using BITNET, and Rose-Hulman and Cal Poly have transferred files between them. There was a PROPI/PC PILOT training session for the members of the Consortium at Cal Poly in January, 1989. A mailing list of interested faculty and a newsletter was distributed in April, 1989.

The Consortium plans to complete their modules by September, 1989 and then share the modules with each other for evaluation. The three specifications will be based on the experience during the development cycle effort as well as evaluations of the four modules. In addition, a Development Manual documenting the creation of the module will be promulgated.

Plans

A new proposal was submitted to NSF in February, 1989 requesting funding for a two-year continuation to set up a new self-sustaining organization at the end of the three-year effort by the Consortium. The members of the Consortium envision adding 24 moremodules to the library, all addressing the first (sophomore) year introduction to electrical engineering. Regional conferences will be held at each university to attract 20 additional universities to the Consortium and to establish a 24-university self-sustaining Association. The following describes these plans in detail.

The Consortium plans to share its expertise and experience with other institutions through the series of regional workshops and the development of a national Association. The Association will be a mechanism through which institutions can share both developmental expertise and the fruits of their development efforts. This
Association will be a network of institutions that develop modules. It will serve as a focal point through which new modules are subject to peer review and existing modules are distributed.

The four-school Consortium believes its collective effort can become a model for shared efforts that address other problems in engineering education. In particular, the administrative structures developed to implement the Consortium and the Association may be applicable to other situations.

To demonstrate a shaced effort in action and to illustrate the potential of the new technologies, the Consortium is focusing its instructional development on the introductory year in the electrical engineering program. The choice has several motivations. First, both majors and non-majors take an introduction to circuits and electronics, usually in the sophomore or junior year. Second, introductory curricula at over two hundred and fifty institutions are similar, so that the results of the Consortium's effort may be of interest to a large audience. Third, the al ternative learning environment offers a vehicle for introducing modeling and design in the introductory year. Recent task forces and workshops have identified modeling and design as topics which require more emphasis in the introductory year. Fourth, investment in the introductory year will return payoffs in the later years of students' education. For these four reasons, the Consortium believes that concentration on the introductory electrical engineering courses will have the biggest impact on engineering education for expenditure of efforts.

\section{Regional Workshops}

To have any appreciable effect on electrical engineering education and future curricula, technologically-assisted instruction in general, and interactive videodisk in particular, must engage the widespread participation of EE faculty as authors and creators of instructional modules. Some would argue that the complexity of coding of this type of work demands the talents not of teachers of electrical engineering, but of highly competent systems programmers from the ranks of computer science. The existence of the Consortium is based on the contrary view; we believe that pedogogic considerations are uppermost in the question of who should author. We see the emergence of powerful authoring software as essentially removing the "complexity factor" from the picture.

The first year of Consortium experience has reinforced the hypothesis that EE faculty, with appropriate facilities and support, can create effective instructional modules using interactive video. There's no question that our first efforts show the slow startup features of any pioneering activity, but the lessons learned as we gain experience are considerable and valuable. We wish to share that experience and learning 
with others as we embark on our goal of creating an Association from the early work of the Consortium.

The first step is to conduct a Regional Workshop/Conference (others to follow, modified to reflect experience with the first). One such workshop was held at Cal Poly on January 20-22, 1989 , for the Consortium members themselves.

A region is understood as encompassing several states, e.g., New England, and at least ten electrical engineering departments. Each department will be invited to send two participants; total attendance should not exceed twentyfour. This constraint is dictated by capacity factors such as the number of personal computers available in an instructional computation laboratory. The workshop will extend over a threeday period, and will be scheduled to allow attendance without interferring with academic-year teaching responsibilities.

Participants will be expected to bring with them the outline of an instructional micromodule, which will serve as the focus of the participants' programming task. The workshop leaders will offer instruction on the basics of instructional design, content outlining, storyboard construction, control code writing using authoring system software, and the fundamentais of video and disk-playing equipment function and operation.

At the close of the workshop, leaders will discuss with participants what it means to make a commitment to the Association, and will ask them to explore with their department heads and deans the possibility of "signing on." We anticipate that five individuals/departments will wish to join the Association from this workshop and from each of the subsequent (three) workshops in other regions.

A11 Associates will develop their modules using a set of hardware and software specifications published by the Consortium. A11 modules will address introductory topics in electrical engineering, and wil1 be designed to require a mean time of 30 to 50 minutes for execution.

\section{The Association}

The following discussion is based upon two assumptions: 1) the regional conferences at the four universities will be held in the 1989-90 academic year, and 2) by June of 1990 there will be 20 universities committed to developing modules in addition to the four comprising the Consortium. It is planned that by the end of December 1989, the definition of the Association organization will be completed.
In developing a plan for an Association, the Consortium members will have to address at least seven concerns: organizational form, mode of protection of property rights, ownership of instructional materials, marketing, distribution agreements, development agreements, and liabilities and warranties.

Based upon the above seven considerations, a number of possible organizational structures can be proposed for consideration. One plausible scenario is this: The Consortium of four universities will be expanded to an unincorporated nonprofit association, referred to as the Association. The Association could provide the specifications for the modules with respect to authoring systems, hardware, and the user interface. It could act as an editorial board and review panel for prospective modules, and could license a distributor to handle the actual marketing, cataloging, reproduction, and distribution of the modules. It would be expected that the distributor would also provide technical assistance for maintenance of the modules and also provide (for a fee) support to members of the Association for development of modules. The product would be protected through copyright and the ownership of the material would belong to the Association. Support for the organization and for the distributor, licensed by the Association, could be provided by annual fees paid by universities for the modules. The cost of the modules might be based upon the student enrollment in the classes using the modules. For example, an institution in which a class used four modules and enrolled 30 students would pay a price, say of $\$ 2.00$ per student per module, which would result in $\$ 240.00$. It is expected that this fee would be charged directly to the students as a fee for the class like a chemistry laboratory course fee. The money would be divided between royalties for the author and support for the Association and the distributor.

\section{Conclusion}

The presentation at FIE will provide examples of the instructional modules. Experience to date has demonstrated that the development effort for the module is very labor-intensive. The goal of the Consortium is to create an Association (through a series of four Regional Workshops) which will provide a structure for peer-reviewed, parallel development of the instructional modules. The Association will also provide the structure for the distribution of the material. 